\title{
Teoría, metodología y práctica de la producción de posiciones discursivas. (Un ejemplo: El caso de los discursos de la infancia sobre el mundo adulto)
}

Theory, methodology and practice of the production of discursive positions. (An example: The case of childhood discourses on the adult world)

\author{
Manuel Montañés Serrano \\ Universidad de Valladolid (Campus de Segovia) \\ investigacionparticipada@gmail.com (ESPAÑA) \\ Siu Lay-Lisboa \\ Universidad Católica del Norte Chile \\ slay@ucn.cl (CHILE)
}

Recibido: 29.082018

Aceptado: 23.04.2019

\section{RESUMEN}

En este artículo se expone una propuesta con la que producir materia prima discursiva, así como su análisis con el que dar cuenta de las posiciones discursivas que se articulan entre sí, las cuales configuran una estructura relacional y no un mero repertorio de testimonios u opiniones sobre la problemática objeto de estudio. A tal fin, se presenta tanto los aspectos teórico-conceptuales como los metodológico-tecnológicos, y asimismo, con el propósito de ejemplificar la propuesta, se ofrecen algunos contenidos de una investigación cuya finalidad era mostrar las posiciones discursivas sobre las representaciones sociales que la infancia tiene de la población adulta.

\section{PALABRAS CLAVE}

Análisis de discurso, Grupo de discusión, inferencia discursiva, muestra estructural, Posiciones discursivas. 


\begin{abstract}
This article lays out a proposal with which to produce discursive raw material, as well as its analysis with which to account for the articulated discursive positions, which form a relational structure and not a mere repertoire of testimonies or opinions on the problem that is object of study. For this purpose, the theoretical-conceptual in addition to the methodological-technological aspects are presented, along with, with the purpose of exemplifying the proposal, some contents of a research are offered to show the discursive positions on the social representations that childhood has of the adult population.
\end{abstract}

\title{
KEY WORDS
}

Discourse analysis, Discussion group, discursive inference, Structural sample, Discursive position.

\section{INTRODUCCIÓN}

De acuerdo con el enfoque cualitativo-estructural enmarcado en una perspectiva sociopráxica, el lenguaje es considerando no solo un medio sino asimismo como unidad de análisis, dado que con las palabras se construye la realidad social a la par que se habla de ella. En este artículo se enuncia una propuesta con la que producir estas unidades, así como su interpretación y análisis con los que dar cuenta de las posiciones discursivas que se articulan respecto a una problemática objeto de estudio, las cuales configuran una estructura discursiva. Se presentan tanto los aspectos teórico-conceptuales como metodológico-tecnológicos que la sustenta. Asimismo, con el propósito de ilustrar la propuesta, se exponen aspectos sustanciales del procedimiento seguido en una investigación cuyo objetivo era dar a conocer las posiciones discursivas sobre las representaciones sociales que la infancia (chilena) tiene de la población adulta.

\section{FUNDAMENTACIÓN TEÓRICA}

La propuesta se enmarca en la perspectiva sociopráxica de la realidad social según la cual la realidad es construida, pero ésta no responde al capricho de cada uno/a, sino que emerge al compatibilizar -que no compartir- los sentidos inferidos a los estímulos producidos por los acoplamientos perceptivomotores en las redes en las que estamos obligados a participar para atender nuestras necesidades. La perspectiva sociopráxica defiende una concepción constructivista de la realidad, si bien, este constructivismo es materialista, no idealista. Como dice Montañés, 
"son las condiciones materiales las que nos obligan a construir una u otra realidad. Es por eso que a éste constructivismo se le adjetive de materialista. La realidad construida no responde a la introspección caprichosa de cada cual (como desde un constructivismo abstracto pudiera defenderse), ni tampoco a un determinismo historicista en el que la persona queda programada al servicio de una determinada meta. No nos encontramos en un vacío existencial, como desde un ingenuo solipsismo pudiera considerarse en el que el ego subjetivo y su conciencia fuesen lo único real, somos seres sujetado a un contexto sociohistórico, que también habita en nosotros, siendo en la singularidad de cada sujeto la instancia en donde se produce la realidad objetual" (Montañés 2012: 453).

Así es, no hay una realidad externa al sujeto, más allá de la energía circundante. Asumir este supuesto de reflexividad (Ibáñez 1985) en el estudio de las ciencias sociales implica también asumir que no es posible escapar de la dialéctica objeto-sujeto (Canales, Opazo y Cottet 2016). Los seres humanos accedemos al mundo representándonoslo, infiriendo sentidos a los estímulos recepcionados. Por medio de nuestras prácticas y discursos - que son tanto decires como haceres- producimos y reproducimos la realidad. Como asegura Montañés,

"con las palabras no sólo decimos — dimensión semántica- sino que también hacemos cosas — dimensión pragmática-. Y si lo dicho tanto designa cosas — componente referencial- como nos permite relacionar unas palabras con otras — componente estructural-, el estudio del hacer de lo dicho, nos permite conocer (hablando con más propiedad, nos permite inferir) una imagen de quien dice lo que dice; dado que al decir quedamos dichos en lo dicho - compromiso sociolingüístico-“" (Montañés 2010: 2).

De ahí la pertinencia de considerar el lenguaje como unidad de análisis y no solo como medio para registrar opiniones o testimonios. El lenguaje es la herramienta mediante la cual los sujetos construimos nuestras realidades y nuestro conocimiento, la herramienta con la que interactuamos y nos relacionamos con otros sujetos. No podemos entender al sujeto como mero individuo. Sujeto es "quien habla", quien enuncia, ya que es por medio del lenguaje como el ser humano se constituye como sujeto (Benveniste 1971). Con, y a través del lenguaje, vamos creando y recreando nuestros itinerarios vitales, nuestros aprendizajes, nuestros saberes y nociones sobre el mundo. El lenguaje "es el mecanismo a través del cual ocurre la negociación del significado" (Mota de cabrera y Villalobos 2007: 413), y representa un vínculo fundamental entre el mundo sociocultural y el funcionamiento mental del individuo. El discurso, aunque sea elaborado en el interior del individuo, y pueda decirse que es tanto interior como exterior, es social. "La mente se extiende más allá de la piel" (Wertsh 1991: 90) y se encuentra vinculada con otras mentes de otros sujetos. El discurso social es dinámico, cambiante y múltiple, tiene contradicciones, matices y variaciones. "El lenguaje es siempre dialógico (no meramente lógico) y conativo (o práxico: se hacen cosas con palabras)" (Colectivo Ioé 2010: 75). Los/as hablantes proporcionan perspec- 
tivas cambiantes, inconsistentes, contradictorias y variadas en sus mundos sociales (Wetherell y Potter 1996). El discurso social puede ser entendido como una práctica social y los sujetos no tenemos una práctica, un discurso social único y acabado, sino más bien producimos unos u otros discursos sociales, dependiendo de la función que estos discursos cumplan, pues están al servicio de las personas y son intercambiables respecto de la perspectiva y momento en que cada sujeto esté (Wetherell y Potter 1996 y Gee 2005).

A diferencia de los estudios cuantitativos estadísticos donde las unidades de análisis son los individuos agregados, en las metodologías cualitativas el concepto de unidad de análisis hace referencia a los elementos que forman parte de un todo y que dan cuenta de la problemática de estudio, los cuales son analizados e interpretados de manera conjunta. Estos pueden provenir de distintas fuentes, y asimismo ser producto de diversas técnicas de producción de datos. También pueden ser cualidades específicas "siempre que se tengan en cuenta los nexos y relaciones que tiene con el todo, los cuales contribuyen a darle su significación propia" (Martínez 2006: 128). Pueden ser el texto de una persona, de una entidad, de un libro, de una imagen o de vídeo, es decir, un producto textual determinado. En la investigación que ilustra la propuesta, las unidades de análisis han sido los textos producidos por niños y niñas en los grupos de discusión en los que participaron.

Estudiar los discursos sociales nos permite dar cuenta de las diversas posiciones discursivas que se estructuran respecto a una problemática objeto de estudio. Jorge Ruiz entiende las posiciones discursivas como

"papeles discursivos típicos socialmente definidos (o roles) que los sujetos adoptan en sus prácticas discursivas concretas [...] pero en el análisis contextual no interesa tanto el carácter más o menos generalizable de estas posiciones, cuanto su consideración como estrategias discursivas adoptadas por los sujetos. Las posiciones discursivas, entendidas en este sentido, permiten reconstruir las interacciones comunicativas mediante las que el discurso se ha producido y, de esta manera, comprender mejor su sentido desde el punto de vista de los sujetos implicados en las mismas" (Ruíz 2009: 6).

Las posiciones discursivas se estructuran en relación a la posición más dominante, estableciéndose con ella distintas relaciones de interdependencia, forjándose un entramado relacional entre las distintas posiciones discursivas (Conde 2010). Se producen, entre otras, relaciones de afinidad, complementariedad, oposición, diferencia, etc. Por consiguiente, no constituyen un mero repertorio de posiciones sino que conforman una estructura relacional (Lay y Montañés 2013). Al articularse una estructura relacional es factible representar gráficamente, en un espacio o campo visual, las posiciones discursivas y las relaciones que tienen lugar, constituyendo un entramado ideológico discursivo. Las posiciones integran contenidos que funcionan como coordenadas ubicando un determinado discurso en un entramado ideológico. Cada posición da cuenta no sólo de lo que se dice, sino 
también qué se dice cuando se dice lo que se dice, de qué o/y de quién se dice, por qué o/y para qué se dice y desde dónde se dice.

En el proceso de análisis, quien investiga, recurriendo a la inferencia discursiva, puede dar cuenta de las posiciones discursivas reificando en un significante la trama ideológico-discursiva, definiendo y conceptualizando cada una de ellas y elaborando la estructura relacional discursiva. Asimismo, podrá construir y representar de manera gráfica la ubicación y relación de las diversas posiciones.

\section{METODOLOGÍA}

La metodología de ésta propuesta invita a reformular y reconstruir el proceso estandarizado. El diseño que se propone es dinámico, procesual, circular y recursivo. No es un proceso de búsqueda sino de producción. No se trata de una "caza" de datos, sino más bien, producción de información. $\mathrm{O}$, dicho de otro modo, los datos son datas no capta, no están ahí para ser capturados, son producidos. Quien investiga, cuando procede a analizar e interpretar sociológicamente los textos generados por la aplicación de cualesquiera de las técnicas conversacionales, no registra sino que produce discursos sociales (Conde, 2010), que, como todo ser humano, ha de compatibilizar, si bien, en este caso es con la comunidad científica y académica, o con el cliente que contrata sus servicios o con la comunidad objeto de estudio, cuando se procede a la devolución creativa en una investigación de índole participativa (Villasante 2006).

Tras una etapa dedicada a la revisión bibliográfica, se enuncian los objetivos, se formulan las hipótesis, se fijan las unidades muestrales, se describen las técnicas a emplear y demás elementos de una investigación, si bien, todos se encontrarán supeditados al propicio proceso investigador, el cual se irá redefiniendo de acuerdo con el fin de dar cuenta de las posiciones discursivas que se articulan respecto a la problemática objeto de estudio. Este proceso requiere la aplicación de técnicas cualitativas/estructurales, que habría que denominarlas más bien prácticas que técnicas. Son prácticas porque son técnicas flexibles en su planificación y ejecución, siempre al servicio del propio proceso de producción y no a la inversa. La práctica de investigación más potente para este propósito es el grupo de discusión. El grupo de discusión es una práctica investigadora con la que se obtiene, mediante un número reducido de reuniones grupales -que se han de grabar, al menos en audio-, la pertinente materia prima discursiva, cuyo análisis servirá para dar cuenta de las representaciones e imágenes colectivas, así como las estructuras relacionales que se articulan respecto a una problemática objeto de estudio. En cada reunión grupal entre cinco y nueve personas, que no se conocen, conversan y se interpelan entre sí, generándose, de este modo, la textura discursiva sobre el tema objeto de estudio (Ibáñez 2003). Las reuniones son oficiadas por un preceptor (Ibáñez 2003) o prerceptora. En este artículo, por economía expositiva se empleará el término usado por el autor citado. El papel del preceptor es fundamental en el desarrollo de la reunión. Su presencia influye en el ritmo y formas de la discusión. Se diferencia del entrevistador de los focus group (Merton el all. 1956) en que actúa de "forma 
más flexible, abierta y menos directiva" (Callejo, 2001:17), y en que busca la interpelación mutua entre los participantes.

El preceptor debe explicitar su rol y presencia en el grupo, advirtiendo que él no forma parte del grupo y que son los participantes quienes informan, en el sentido que dan forma al grupo. Ha de procurar que los temas fluyan de manera espontánea y no imponerlos. Ha de provocar ${ }^{1}$, producir desencuentros en el encuentro, donde emerjan las contradicciones y las refutaciones, articulándose, de este modo, las argumentaciones, para así dar cuenta de los encuentros, de los tópicos/típicos, esto es, de los discursos socialmente compatibilizado en un espacio y tiempo social e histórico, en un aquí y en un ahora. El preceptor ha de estar vigilante para que sus intervenciones, cuando sean necesarias, no rompa la textura discursiva del grupo. Los actuantes saben que el grupo es simulado, pero debe sentirlo como real, han de sentirse cómodos, como si fuese propio de su cotidianeidad. El preceptor se orienta con una guía o carta de navegación, en la que incorpora una serie de preguntas o frases estímulo, caracterizadas por ser poco estructuradas y amplias, las cuales han de invitar a conversar, sugerir y provocar sin que ello restrinja, ni mucho menos condicione la discusión, y que puedan servir de apoyo en el caso de que no se genere caudal discusivo. Es necesario no inducir respuestas, ni emitir preguntas cerradas. Esta guía o carta de navegación ha de contener las líneas conversacionales de la discusión, es una carta para navegar en el proceloso mar discursivo, sin senderos y vías estrictas y previamente marcadas, ya que las rutas se irán trazando en el devenir de la discusión. La guía ayudará al preceptor a saber, en todo momento, cuánto se ha recorrido y qué rutas se han navegado, en qué procelosas aguas se encuentra, así como cuánto le falta al grupo por recorrer.

El preceptor debe cerciorarse que los tópicos que dan cuenta de la problemática de estudio sean discutidos, y de no cerrar la posibilidad de que emerjan otros nuevos. A tal fin ha de escuchar sin participar en la discusión y cuando hable lo ha de hacer para lanzar frases estímulos o/y formular preguntas. De acuerdo con Gutiérrez (2008), el preceptor ha de evitar acotar e imponer los temas, dar su opinión personal, aportar o contribuir a aportar contextos y/o referenciados, discutir las opiniones o situaciones en las que se desarrollan la argumentaciones o ideas, justificar o invalidar puntos de vista.

Como se ha dicho, el número de participantes oscila entre 5 y 9 ya que, por un lado, el número mínimo de participantes debe ser mayor a la posibilidad de relaciones que generen los y las hablantes. "Sólo a partir de cuatro actuantes el número de canales posibles es mayor que el número de elementos" (Ibáñez 2003: 273). Por otro lado, a partir de 10 el grupo se fragmentaría, se disgregaría, creando subgrupos. La discusión que se sostenga en el grupo exige, para cada participante, la sincronización de las recepciones de las actuaciones de los otros, y es imposible atender a más de seis personas hablando. Un grupo de más de nueve personas solo funciona si una parte se calla (Ibáñez 2003).

1 "Provocar quiere decir literalmente "hacer hablar", hacer pasar a la palabra (para que diga lo no dicho, e incluso, se intente decir lo no decible)" (Ibáñez 1986: 57) 
Para establecer el número de grupos que se han de realizar, así como la composición de cada uno, se ha de confeccionar una muestra estructural que represente una red de relaciones, de modo que cada participante puede entenderse como una posición, en una estructura (Canales 2006: 282). Este tipo de muestra se basa en reproducir las relaciones sociales relevantes que se articulan en relación con la problemática objeto de estudio. Por tanto, cada muestra estructural solo es válida para cada problemática y su población objeto de estudio, pues, como dice Jesús Ibáñez (1985), las técnicas estructurales se sustentan en un empirismo concreto, a diferencia del empirismo abstracto de técnicas distributivas como la encuesta. Manuel Montañés, al respecto, sostiene que la muestra estructural "no responde a criterios estadísticos estratificados, ni a la mera yuxtaposición acrítica de estructuras sociales" (Montañés 2013: 1). Asimismo, Julio Mejía (2000) señala que "cada unidad seleccionada expresa la posición diferencial [respecto] del objeto de estudio y todas juntas reproducen en su composición y dinámica las relaciones sociales del objeto" (Mejía 2000: 167). La muestra estructural selecciona a los/as participantes por criterios de comprensión y de pertinencia, donde la saturación y su representatividad vienen dadas por incluir todos los grupos que reproduzcan mediante sus discursos relaciones relevantes para nuestro objeto (Ibáñez 2003). Como apunta Luis Enrique Alonso: "los participantes producen discursos tópicos del grupo social al que pertenecen" (Alonso 1998: 106). El análisis de la materia prima discursiva generada por todas y cada una de las reuniones grupales ha de dar cuenta de todos los posibles discursos sociales respecto a la problemática de estudio, en un ámbito socio-espacio-temporal determinado, produciéndose así la representatividad discursiva (Lay-Lisboa y Montañés 2018. La elaboración de la muestra estructural requiere, por consiguiente, establecer los criterios a seguir en la selección de los ejes estructurales. Un eje estructurador define el área temática, espacio temporal, poblacional (socioeconómica cultural) que determina la configuración y las características de las prácticas conversacionales para la producción de materia discursiva, cuyo análisis dará cuenta de las posiciones discursivas. Estos ejes estructuradores determinan los grupos que, dadas sus relaciones estructuradas, generen la pertinente saturación discursiva. Por tanto, se realizarán tantas reuniones grupales como grupos resulten de la aplicación de los ejes estructurales para así poder dar cuenta tanto de los grandes discursos, aquellos más dominantes, como de los que son más minoritarios, que pueden quedar invisibilizados por los primeros. De acuerdo con Montañés,

"cinco grandes ejes se proponen para estructurar la muestra: clase social, edad, género, grupo convivencial (étnico) y ecológico (hábitat). Si bien, conviene aclarar, por una parte, que no en todos los estudios se ha de contar con esto cinco ejes, y, por otra, que otros ejes, más o menos referenciados con los mencionados, pueden ser los pertinentes. Todo depende de la problemática objeto de estudio, de los objetivos, finalidad de la investigación y del universo poblacional objeto de observación. Si se define correctamente la problemática objeto de estudio, el universo poblacional de observación queda implícito en el mismo, pues, como se sabe, la problemática se define de acuerdo con 
tres parámetros fundamentales, como son, el tema, el ámbito y la población" (Montañés 2010: 6).

La conformación de cada reunión grupal debe responder en primer término a criterios de homogeneidad, ya que se pretende que en los grupos de discusión no se reproduzca relaciones asimétricas, de poder o de desigualdad, pero para que se genere el debate es necesario introducir cierta heterogeneidad inclusiva. Si no existen matices entre los hablantes, ni desencuentros, no existirá interpelación, con lo cual no habría fracturas ni contradicciones, no habría intercambio. No se dispondrá de textura discursiva (o, al menos, no con la extensión e intensidad necesaria), lo que provocaría un discurso plano y uniforme, no obstante, la heterogeneidad inclusiva no ha de provocar diferencias demasiado amplias. Ha de enriquecer la diversidad de cada grupo sin perderse el criterio de homogeneidad por el cual el grupo ha sido diseñado. Esto es, se ha de evitar que la diversidad o heterogeneidad que se introduzca en los grupos no se solape con el criterio que ha justificado la conformación de un grupo u otros grupos. Ya que la existencia de cada grupo no obedece a un repertorio de categorías, sino que conforma una estructura. Se convendrá que no dirán lo mismo ni del mismo modo, los/as empleados/as en presencia de sus empleadores/as, que estando sin ellos/as. Lo mismo ocurre, por ejemplo, con los niños y niñas frente a sus padres y madres. Es así con todo grupo social que se enfrente en una relación de desigualdad que signifique la dominación de un grupo sobre otro. Por esta razón no puede haber entre los y las participantes del mismo grupo de discusión relaciones desiguales y de poder.

En las investigaciones que contemplan solo dos ejes, éstos se cruzarán a modo de ordenadas y abscisas de un cuadrante cartesiano. Previamente cada eje será segmentado siguiendo o bien un criterio analógico de más/menos, o un criterio digital nominal (designándose categorías del tipo jóvenes, adultos, ancianos) o un criterio extensivo no métrico (del tipo mucho, poco, o alto, medio, bajo), o bien otro criterio que se estime relevante. El cruce determinará las reuniones grupales a realizar, si bien, conviene tener siempre presente que no se trata de asignar tantas reuniones como celdillas resulten del cruce de los segmentos en los que se han distribuido los ejes sino según se consideré que cada una es homogéneamente diferente de las otras y en su interior alberga la pertinente heterogeneidad inclusiva. Cuando la muestra contempla más de dos ejes, se cruzarán las categorías de los ejes teniendo presente la advertencia recién mencionada. No se hará siguiendo una aséptica rutina topológica sino de acuerdo con la homogeneidad y la heterogeneidad inclusiva que cada una de las reuniones grupales ha de contener. A tal fin se ha de prestar atención para que, por un lado, la reunión grupal resultante del cruce no quede desvirtuada de tal modo que carezca de utilidad para captar la especificidad discursiva que ha aconsejado designar el eje y sus correspondientes categorías, y, por otro lado, para que la heterogeneidad inclusiva aportada por el cruce no sea de tal envergadura que en vez de ejercer de adjetivo lo haga de sustantivo y rompa la pertinente homogeneidad grupal. En este artículo, en el apartado dedicado a la ejemplificar la propuesta, siguiendo el procedimiento formulado por Montañés 
(2013 y 2014) y Montañés y Lay (2016 y 2017), se expone el modo de proceder en el diseño de una muestra estructural que contemple más de dos ejes.

Para dar cuenta de las posiciones discursivas y la estructura que configuran, se debe superar la ortodoxia de un manual canónico dispuesto de estrictas pautas de desarrollo, análisis e interpretación. Es más bien un trabajo de tipo artesanal, propio de un oficio, del que se conoce cómo usar unas u otras herramientas, amparado en la formación adquirida en la experiencia de los trabajos realizados, siendo cada uno singular e irrepetible.

Como señala Montañés se puede

"elegir entre dos modos de proceder en la interpretación de discursos. Uno, consiste en analizar cada texto producido en cada entrevista individual o grupal; el otro, en analizar la agrupación de los fragmentos discursivos extraídos de cada entrevista individual o grupal que hacen referencia a cada uno de los bloques temáticos considerados [...] Una y otra opción nos exige proceder de manera espiralada, esto es, nos obliga a observar lo dicho en relación a otros dichos -en el caso de la primera opción-; y a fijarnos en quién dice lo que se ha dicho -en el caso de la segunda opción. De esta manera se construyen inacabados círculos que propician otros igualmente inacabados en un nivel superior, y así sucesivamente (Montañés 2002: 98-99).

En la investigación a la que se ha recurrido para ilustrar el proceso interpretativo se adoptó la segunda opción, ya que se quería mostrar las diversas posiciones discursivas del conjunto de la población sobre la problemática objeto de estudio y no las que se pudieran extraer de cada uno de los textos producidos en cada uno de los grupos de discusión realizados.

El análisis del material producido en los grupos de discusión se realiza, como se puede observar en la Tabla 1, en dos fases, una primera denominada organización y una segunda denominada inferencia discursiva. Además, hay una fase previa, denominada preparativo, consistente en la transcripción literal de "lo dicho" en los grupos de discusión. 


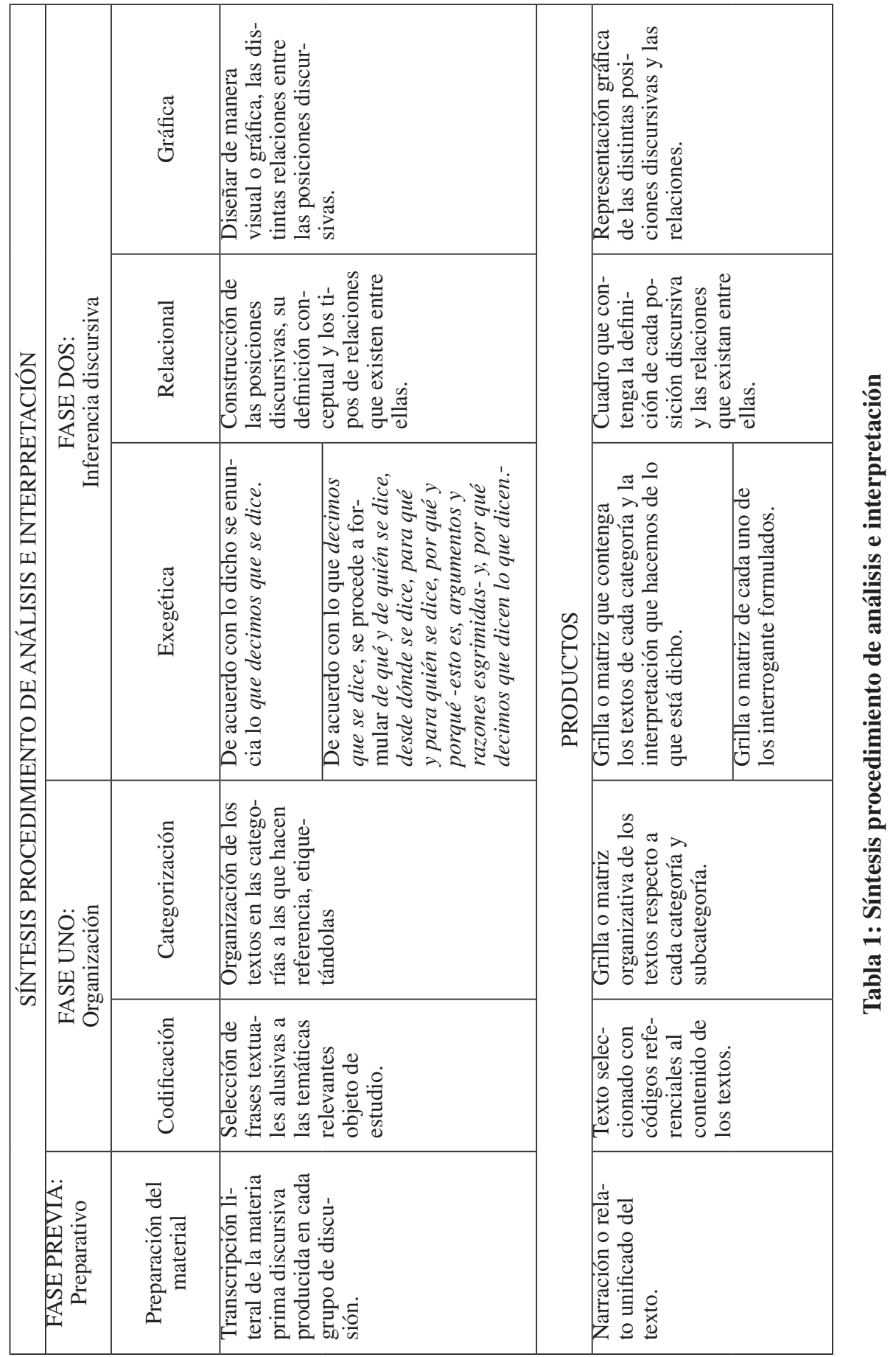

EMPIRIA. Revista de Metodología de Ciencias Sociales. N. ${ }^{\circ} 43$ mayo-agosto, 2019, pp. 89-115. ISSN: 1139-5737, DOI/ empiria.43.2019.24300 
La fase de organización, se divide a su vez en dos etapas: la codificación y la categorización. En la etapa de codificación, recurriendo a colores, letras o números, se identifican y etiquetan los fragmentos textuales que hacen alusión a las temáticas y subtemáticas previamente formuladas. Las múltiples lecturas podrán aconsejar que se reformulen los temas y subtemas o/y que se formulen otros nuevos en la etapa dedicada a la categorización, en la que quedan agrupados los múltiples y diversos fragmentos textuales que hacen referencia a cada una de ellos. Para facilitar el análisis cada fragmento llevará consignado un código de identificación referido a la reunión grupal en el que se ha producido. Asimismo, es pertinente reseñar que en cada categoría se agrupan todos los fragmentos que hacen referencia a la temática contemplada en la misma, si bien, un fragmento discursivo puede hacer alusión a diversas categorías. En esta fase se produce una grilla o matriz que alberga los textos de acuerdo con las categorías elaboradas, las cuales se interpretarán en la segunda fase recurriendo a la inferencia discursiva. La segunda fase contempla tres etapas: la exegética, la relacional y la gráfica. La etapa exegética es la más interpretativa del proceso de análisis, si bien, todas las fases y etapas son interpretativa, "ya que incluso aunque únicamente se expusieran frases textuales, la propia selección de las mismas habría que considerarlas un modo de dar cuenta de la interpretación efectuada" (Montañés 2009: 111). En esta fase, lo primero es agrupar los diferentes textos que hacen referencia a cada temática en grupos discurso. Entendiéndose por grupo discurso, la agrupación por similitud de contenido y de argumento, los fragmentos que expresan distintas opiniones o puntos de vista respecto a cada categoría y subcategoría. A tal fin se recurrirá a la dimensión semántica del leguaje tanto en su dimensión referencial, o sea, qué se dice ${ }^{2}$, como estructural, esto es, enunciado lo que se dice al decir lo que se dice, vale decir, lo que quien investiga dice que se dice. Ello produce una matriz que alberga todas las categorías, sub-categorías y los diversos Grupos discursos identificados con sus respectivos fragmentos textuales producidos en los grupos de discusión. En un segundo momento, en cada grupo discurso, recurriendo a la inferencia discursiva, se formulan las respuestas a los siguientes interrogantes: de quién o de qué se dice ${ }^{3}$, por qué se dice lo que se dice, esto es, qué argumentos se aducen ${ }^{4}$, desde dónde se dice ${ }^{5}$, y para legitimar la interpretación realizada, se ha de decir por qué decimos - por qué dice quien investiga que dicen lo que dicen ${ }^{6}$. Las respuestas a estas interrogantes

${ }^{2}$ Estos serán los fragmentos que llaman la atención de quien investiga. Permiten la interpretación, y dan cuenta de las distintas posturas ante cada temática de estudio.

${ }^{3}$ Sobre qué, quién o quiénes se hace referencia al decir lo que se dice.

${ }^{4}$ Cuáles serían las argumentaciones que se exponen-o aluden- para decir lo que se dice, esto es, que se dice para sustenta los dichos.

5 Desde qué concepciones se parte para decir lo que se dice, cuáles serían los núcleos centrales del discurso que incitan a decir lo que se dice.

${ }^{6}$ Qué argumentos esgrimimos para legitimar la interpretación realizada. Ello requiere recurrir a la dimensión anafórica y deíctica del lenguaje, esto es, a la facultad del lenguaje para reproducir palabras dichas o por decir, y al ámbito extralingüístico que nos remite al contexto situacional que dan sentido a las palabras pronunciadas, esto es, a los textos producidos por los participantes en las reuniones grupales y al ámbito sociocultural de referencia de los grupos en donde son producidos los 
permiten elaborar las posiciones discursivas, su definición conceptual y los tipos de relaciones que existente entre ellas, ya sean, como se ha dicho, de afinidad, complementariedad, oposición, diferenciación, etc. Por último, en la etapa gráfica, para que se visualice las posiciones y sus relaciones, se ha de proceder a representarlas gráficamente.

\section{EJEMPLO CON EL QUE ILUSTRAR LA PROPUESTA METODOLÒGICA}

La investigación con la que se propone ejemplificar la propuesta presentada, se realizó en distintas ciudades de Chile con niños y niñas de entre 10 y 14 años. El propósito era conocer las diversas nociones que la infancia construye sobre el mundo adulto y sus relaciones con el mismo mismo, sobre la escuela y el sistema educativo, y respecto a sí misma. El estudio se estructuró en cinco grandes etapas. La primera de ellas respondió al levantamiento de un cuerpo teórico y la consecuente (re)búsqueda que afinase dicho cuerpo, se elaboró el marco referencial de la problemática objeto de estudio, se fijaron los objetivos, se estableció la metodología y se designaron las técnicas de investigación, se formularon las hipótesis, se definieron las unidades de análisis y se enunciaron las fuentes a las que acudir. La segunda remitió al diseño y planificación metodológica del trabajo de campo. Se pretendía conocer y tomar contacto con los niños y niñas en ámbitos en los que se encuentran cotidianamente. La tercera etapa fue destinada al trabajo de campo y a la aplicación de las prácticas de producción de discurso. La cuarta etapa se dedicó al análisis e interpretación de la materia prima proporcionada en el trabajo de campo, configurando un escenario o diagnóstico, con el que, en una quinta etapa, ofrecer las posiciones discursivas al respecto, así como sus relaciones.

Para recoger la materia prima discursiva pertinente se recurrió al grupo de discusión, elaborándose para tal fin una guía o carta de navegación. En la tabla 2 se expone un fragmento de la guía o carta de navegación que orientó la discusión. Se puede apreciar cómo se van desglosando - de izquierda a derecha - los tópicos a discutir, para el caso se han considerado dos dimensiones del estudio -adultez y relación adultez/niñez- hasta llegar a las frases estímulos, a las que se recurrió para provocar la discusión. En la primera columna se señalan los objetivos específicos, luego los bloques temáticos del estudio y a continuación se especifican los sub-bloques en los que se desglosan. En las dos columnas posteriores se señalan las preguntas directrices y frases estímulos respectivas, que hacen referencia a las columnas previas. Se sitúan en esta última los enunciados menos estructurados, aquellas locuciones —estímulos discursivos-dispuestos a facilitar la conversación.

mismos. 


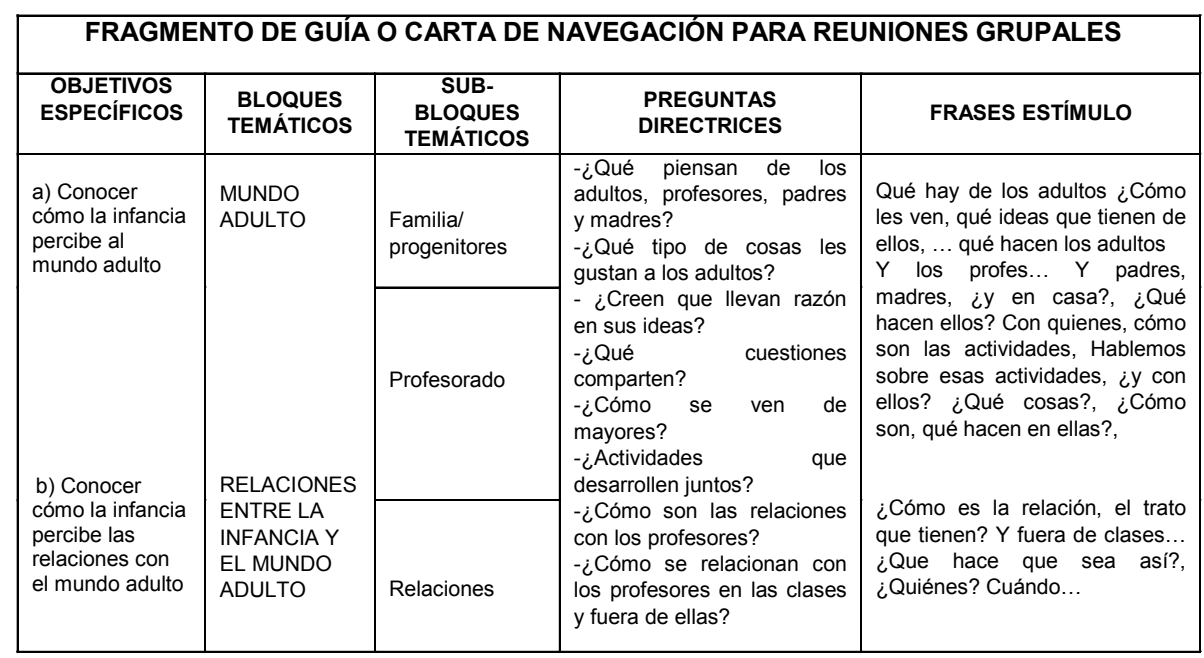

Tabla 2: Fragmento de guía o carta de navegación para reuniones grupales

Diseñada la carta de navegación, se procedió a confeccionar la muestra es-tructural con la que determinar el número de grupos de discusión a realizar y la composición de cada uno. Se consideraron los siguientes ejes estructurales: hábi-tat, espacio educativo, ideología familiar (estructurado por la clase y la religión), sexo-género y edad. Estableciéndose, como se puede apreciar en la tabla 3, diez grupos de discusión. 


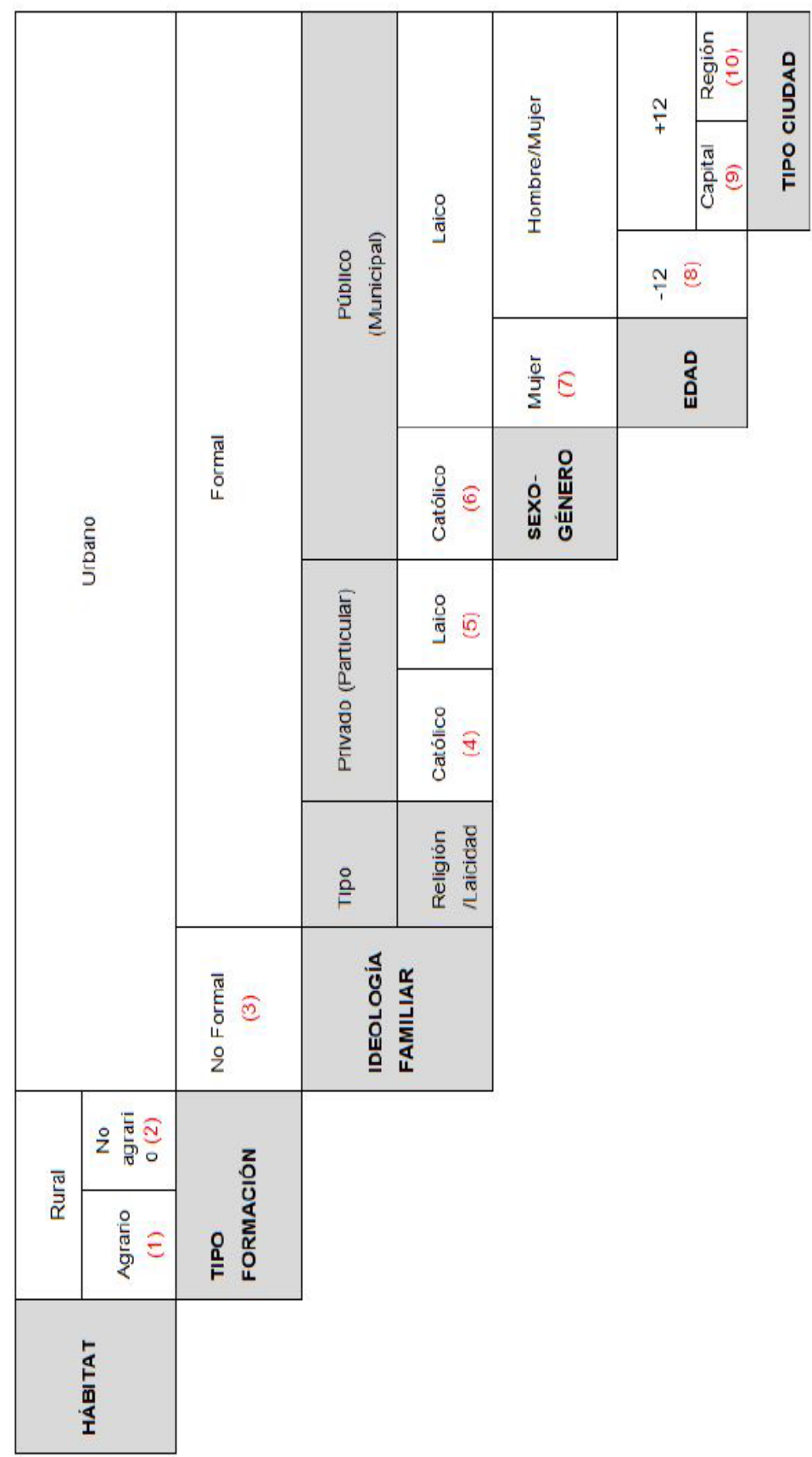

 
La muestra estructural se ha de leer arriba abajo y de abajo arriba, de izquierda a derecha y de derecha a izquierda. Como se puede apreciar en la tabla 3, se distinguen los siguientes grupos de discusión: para el eje hábitat, zona rural y urbana, y para la zona rural, (1) uno agrario y (2) otro no agrario. El ámbito formativo constituye otro eje estructurador el cual establece dos categorías: la educación formal y (3) la no formal, es decir, donde tiene lugar las iniciativas educativas alternativas a la educación escolarizada. Otro de los ejes es la ideología familiar. Para este estudio, se ha configurado de acuerdo con la clase social y la religiosidad de los/as padres/madres de niños y niñas. Estableciéndose los correspondientes grupos de discusión en los colegios respectivos, (4) católico privado, (5) católico laico, y (6) católico público. Se ha considerado, asimismo el sistema sexo-género como eje estructurador, pues se entiende que entre las niñas hay aspectos discursivos que se diferencia del discurso generalizado (7). La edad también se ha fijado como uno de los ejes estructuradores, estableciéndose una distinción entre una (8) infancia más joven y (9) una infancia mayor. Además, al objeto de captar la eventual diferencia entre ciudades según sea su tamaño y relevancia sociopolítica, se realizó una reunión grupal en (9) la capital, Santiago de Chile, y otra en (10) la región de la zona norte, en la ciudad de Antofagasta.

Resumiendo, como se puede ver en la tabla 4, los 10 grupos de discusión respondieron a las siguientes características:

\section{FICHA TÉCNICA DE LOS GRUPOS DE DISCUSIÓN}

(G.1) Niños y niñas, urbano, educación formal establecimiento educativo público/municipal, laico.

(G.2) Niños y niñas, urbano, educación formal establecimiento educativo privado/particular, religioso.

(G.3) Niñas, urbano, educación formal establecimiento educativo público/municipal, laico.

(G.4) Niños y niñas, urbano, educación formal establecimiento educativo público/municipal, religioso.

(G.5) Niños y niñas, urbano, educación no formal, laico.

(G.6) Niños y niñas, urbano, educación formal establecimiento educativo público/municipal, laico, región.

(G.7) Niños y niñas, urbano, educación formal establecimiento educativo particular/privado, laico.

(G.8) Niños y niñas, rural, no agrario, educación formal establecimiento educativo público/ municipal, laico.

(G.9) Niños y niñas, urbano, educación formal establecimiento educativo público/municipal, laico, capital.

(G.10) Niños y niñas, rural, agrario, educación formal establecimiento educativo público/ municipal, laico.

Tabla 4. Ficha técnica de los Grupos de discusión. 
De acuerdo con la muestra diseñada se constituyeron y realizaron las correspondientes reuniones grupales, las cuales fueron grabadas en audio, cuya transcripción literal constituyó la unidad de análisis. Hecha la transcripción, se procedió a la interpretación. A tal fin, en una primera fase se organizó del material producido, y en una segunda, recurriendo a la inferencia discursiva, a la formulación de las posiciones discursivas, y a la representación gráfica de las mismas.

En una primera etapa dedicada a la organización se procedió a la codificación del material discursivo. Se etiquetaron los fragmentos que hacían referencia a uno u otro tema o subtema, o que sugerían matizar los bloques y sub-bloque ya contemplados o la enunciación de otros que inicialmente no estaban formulados.

En la fase dedicada a la categorización, quedaron agrupados los fragmentos que hacen referencia a cada bloque y respectivos sub-bloques enunciados en la tabla 5, asignándose los códigos correspondientes para identificar la reunión grupal en la que fueron producidos.

\begin{tabular}{|c|c|c|}
\hline $\begin{array}{c}\text { BLOQUES } \\
\text { TEMÁTICOS } \\
\end{array}$ & $\begin{array}{l}\text { SUB-BLOQUES } \\
\text { TEMÁTICOS }\end{array}$ & DESCRIPCIÓN \\
\hline \multirow{3}{*}{$\begin{array}{l}1 . \\
\text { REPRESENTACIONES } \\
\text { SOCIALES SOBRE } \\
\text { LA POBLACIÓN } \\
\text { ADULTA }\end{array}$} & 1.1 GENERAL & $\begin{array}{l}\text { Modos en que la infancia ve a las } \\
\text { personas adultas. }\end{array}$ \\
\hline & 1.2 PROFESORADO & $\begin{array}{l}\text { Da cuenta de cómo la infancia } \\
\text { percibe al profesorado. }\end{array}$ \\
\hline & 1.3 MADRES/PADRES & $\begin{array}{l}\text { Modos en que la infancia percibe a } \\
\text { las figuras paternas y maternas. }\end{array}$ \\
\hline \multirow[b]{2}{*}{ 2. RELACIONES CON } & 2.1 PROFESORADO & $\begin{array}{l}\text { Da cuenta de cómo se relaciona } \\
\text { la infancia con la figura del } \\
\text { profesorado. }\end{array}$ \\
\hline & 2.2 MADRES/PADRES & $\begin{array}{l}\text { Descripción de cómo se relaciona } \\
\text { la infancia con los adultos en } \\
\text { el ámbito doméstico/familiar. } \\
\text { Descripción de los roles en el } \\
\text { ámbito del espacio doméstico. }\end{array}$ \\
\hline \multirow{3}{*}{$\begin{array}{l}\text { 3. PERCEPCIONES Y } \\
\text { VALORACIONES DEL } \\
\text { SISTEMA ESCOLAR }\end{array}$} & $\begin{array}{l}\text { 3.1 ORGANIZACIÓN- } \\
\text { ESTRUCTURA } \\
\text { INSTITUCIONAL DE } \\
\text { LA ESCUELA }\end{array}$ & $\begin{array}{l}\text { Descripción que la infancia hace } \\
\text { de la escuela y la educación. } \\
\text { Apreciaciones sobre la calidad de } \\
\text { la educación. }\end{array}$ \\
\hline & $\begin{array}{l}\text { 3.2 METODOLOGÍA/ } \\
\text { PEDAGOGÍA }\end{array}$ & $\begin{array}{l}\text { Valoración de la infancia de } \\
\text { las actividades y metodologías } \\
\text { educativas. }\end{array}$ \\
\hline & $\begin{array}{l}3.3 \text { USO Y } \\
\text { APROPIACIÓN DE } \\
\text { LOS ESPACIOS }\end{array}$ & $\begin{array}{l}\text { Descripción de cómo la infancia } \\
\text { describe y usa los lugares y } \\
\text { espacios escolares. }\end{array}$ \\
\hline
\end{tabular}

Tabla 5. Bloque, sub-bloques y descripción

Una vez elaborados los diferentes textos compuestos por los fragmentos que hacen referencia a cada bloque y sub-bloque, se inició la segunda fase, que, a su vez, se estructuró en tres etapas: Exegética, Relacional y Gráfica. En la Exegéti- 
ca, en un primer momento se elaboraron los múltiples grupos discursos de cada bloque temático, esto es, lo diferentes fragmentos de cada tópico contemplado. A tal fin se confeccionaron las matrices de acuerdo a lo que se dice y qué se dice al decir lo que se dice. En la tabla, como se puede ver en la tabla 6 se expone uno de los múltiples grupos discursos elaborados.

\begin{tabular}{|l|l|}
\hline \multicolumn{1}{|c|}{ SOBRE QUÉ SE DICE I RELACIONES I ACTORES SOCIALES ADULTOS: PROFESO- } \\
\hline \multicolumn{1}{|c|}{ QAUÉ SE DICE } & \multicolumn{1}{|c|}{ QUÉ DECIMOS QUE DICEN } \\
\hline $\begin{array}{l}\text { A mí lo que me molesta es que los profesores } \\
\text { a veces se toman el derecho de gritarnos, de } \\
\text { retarnos por cualquier cosa, porque a veces el } \\
\text { profesor dice... nos grita y tampoco se pone } \\
\text { a pensar que hay niños que no sé poh, tienen } \\
\text { problemas en la casa [...] Es que tienen que } \\
\text { ser empáticos (G.1) }\end{array}$ & $\begin{array}{l}\text { Los profesores, en algunos casos, faltan el } \\
\text { respecto a los alumnos, no los consideran } \\
\text { como iguales. Se dice que los profesores } \\
\text { no logran ponerse en el lugar de los estu- } \\
\text { diantes. }\end{array}$ \\
\hline $\begin{array}{l}\text { A veces el profe. Es que tienen mucho poder en } \\
\text { mala ... eso es verdá (G.1) }\end{array}$ & $\begin{array}{l}\text { Se habla de una relación asimétrica entre } \\
\text { los profesores y los estudiantes. Esto es, } \\
\text { hay una relación de subordinación. }\end{array}$ \\
\hline $\begin{array}{l}\text { Que las profesoras son como las que más se } \\
\text { acercan al curso, ellas como que siempre nos } \\
\text { han conocido entonces, son las que siempre } \\
\text { como que han estado aquí, entonces como que } \\
\text { se involucran con nosotros (G.3) }\end{array}$ & $\begin{array}{l}\text { Las profesoras se involucran más con los } \\
\text { niños, ellos tienen más confianza con ellas, } \\
\text { porque les transmiten una preocupación ge- } \\
\text { nuina, se dice que ellas los conocen desde } \\
\text { más tiempo, por lo que les conocen más. Se } \\
\text { considera que la formación no se ha de des- } \\
\text { contextualizar de las relaciones o vínculos } \\
\text { personales que se establecen entre el profe- } \\
\text { sorado y el estudiantado }\end{array}$ \\
$\begin{array}{l}\text { En el sentido de que como ya no estamos con } \\
\text { el profesor jefe y el profesor jefe es el que } \\
\text { nos apoya en todas las decisiones. Nos apoya } \\
\text { siempre. Nos organiza. Nos ayuda. Nos orga- } \\
\text { niza las ideas, todo eso, lo que podemos hacer } \\
\text { primero, y después... y si no le gusta la idea } \\
\text { no se hace y nos da otras mejores. Sí, influye } \\
\text { en nosotros también porque este año incluso } \\
\text { él quiere que seamos más independientes, pero } \\
\text { igual nos cuesta organizarnos (G.3) }\end{array}$ & $\begin{array}{l}\text { Necesitan muchas veces la relación con una } \\
\text { figura adulta dentro del aula, para que los } \\
\text { oriente, regule y controle. Los profesores } \\
\text { son los que formulan las propuestas, ello } \\
\text { merma la capacidad de iniciativa de los } \\
\text { alumnos. }\end{array}$ \\
\hline
\end{tabular}

\section{Tabla 6. Fragmento Matriz. Ejemplo: Subcategoría Profesorado, categoría Representaciones Sociales}

En un segundo momento, en cada grupo discurso se procedió a inferir el sentido de lo dicho de acuerdo con las siguientes preguntas de interpretación, que en su conjunto contribuyen a configurar las diversas posiciones discursivas: de quién o de qué se dice, qué se dice, qué decimos que dicen, por qué se dice lo que se dice, (esto es, qué argumentos se aducen), desde dónde se dice, y por qué 
decimos -quienes investiga - dice lo que dice, respecto a cada una de las categorías y subcategorías objetos de análisis.

El resultado es una amplia matriz. Al objeto de ilustrar el proceso en la tabla 7 se expone el fragmento referido a la subcategoría Metodología/Pedagogía perteneciente a la categoría Percepciones y valoraciones sistema escolar.

\begin{tabular}{|c|c|}
\hline \multicolumn{2}{|c|}{$\begin{array}{l}\text { SOBRE QUÉ SE DICE I PERCEPCIONES Y VALORACIONES I SISTEMA ESCOLAR: } \\
\text { METODOLOGÍA /PEDAGOGÍA }\end{array}$} \\
\hline Qué se dice & $\begin{array}{l}\text { Yo creo que esa es una buena alternativa para los profesores, para que } \\
\text { ellos hagan las clases bien. Y para calmarnos a nosotros. Sí, incluso } \\
\text { eso nos ayuda a nosotros, si eh... en tecnología eso nos deja concen- } \\
\text { trarnos más. Sí, eso es verdad, como que te relaja más. Y te concen- } \\
\text { tras más... (G.3) } \\
\text { Es que los cursos son como más entretenidos, y se pueden hacer } \\
\text { como más amigos... Son más de prácticas y no solamente hablar de } \\
\text { cosas que a uno le interesa, no es tan teórico (G.5) } \\
\text {... igual es buen método de enseñanza, es que igual nos conoce más } \\
\text { porque como igual recién salió del colegio... o sea de la U. Sí, y } \\
\text { sabe cómo tratarnos, y nos dice qué método preferimos nosotros para } \\
\text { estudiar, es como más moderna, y ella lo hace, por ejemplo yo le dije } \\
\text { que quería que nos hiciera una prueba de una película... y dijo que } \\
\text { era buena idea, que de ahí lo iba a ver (G.6) } \\
\text { Yo encuentro pa mí la mejor es que sea una clase más activa, porque } \\
\text { claro los profes que ya, abran en la página tanto, y escríbanme este } \\
\text { resumen, pero eso aburre, es fome, pero además ya uno lo hace, pero } \\
\text { es latero, entonces uno ya no le presta atención, es fome...(G.7) } \\
\text { A la profesora de lenguaje yo sí le dije porque él nos preguntó de que } \\
\text { qué forma aprendíamos mejor, y nosotros elegimos con power point } \\
\text { porque el año pasado la profe [...] nos hacía con power point, porque } \\
\text { tenía que hablar primero con miles de personas para, como que miles } \\
\text { de cosas... (G.7) } \\
\text { Pero qué, si no va a haber casi participación. No porque, está fome. } \\
\text { No va a haber participación de casi nadie (G.3) }\end{array}$ \\
\hline $\begin{array}{l}\text { Qué decimos que } \\
\text { dicen }\end{array}$ & $\begin{array}{l}\text { Se deberían utilizar la tecnología y metodologías más activas y parti- } \\
\text { cipativas, ya que ello facilita una mayor concentración y aprendizaje } \\
\text { para los estudiantes } \\
\text { Algunos profesores utilizan recursos audiovisuales en clases. Les } \\
\text { hacen partícipes a los niños, y no los ven como niños pequeños sin } \\
\text { criterio sino como estudiantes capaces de dar su opinión. Hay profe- } \\
\text { sores que no les tratan de manera infantilizada. } \\
\text { En la medida que los cursos son más dinámicos y prácticos son más } \\
\text { entretenidos y se aprende mejor, es decir, son más eficaces mientras } \\
\text { más se diferencien de las clases convencionales y centradas solo en } \\
\text { aspectos teóricos. } \\
\text { Cuando restringen las actividades lúdicas, los niños dejan de partici- } \\
\text { par, las consideran aburridas, pues no responde a sus intereses ni se } \\
\text { ajustan al modo de entender la formación. }\end{array}$ \\
\hline
\end{tabular}




\begin{tabular}{|c|c|}
\hline $\begin{array}{l}\text { Por qué se dice lo } \\
\text { que se dice (qué } \\
\text { argumentos se adu- } \\
\text { cen) }\end{array}$ & $\begin{array}{l}\text { Se argumenta que con metodologías más activas y participativas se } \\
\text { comprenden mejor los contenidos. Las sesiones que se apoyan en } \\
\text { recursos tecnológicos propician una mayor concentración, logrando } \\
\text { que las clases sean más dinámicas y entretenidas. Prefieren activida- } \\
\text { des más prácticas, ya que de este modo pueden interactuar con sus } \\
\text { compañeros y aprender más. } \\
\text { Cuando las clases son monótonas no se suscita el interés de los estu- } \\
\text { diantes. Para que las clases sean más eficaces los profesores deberían } \\
\text { invertir más tiempo en conocer a los alumnos, abriéndose a ellos, } \\
\text { e incorporando las ideas de los mismos en la programación de las } \\
\text { sesiones. }\end{array}$ \\
\hline Desde dónde se dice & $\begin{array}{l}\text { Se considera que no es posible desvincular la dimensión lúdica del } \\
\text { aprendizaje, es por ello que se propone la utilización de estrategias } \\
\text { didácticas y metodológicas más lúdicas, con las que facilitar un pro- } \\
\text { ceso de aprendizaje dinámico y eficaz. Se señala esto desde la creen- } \\
\text { cia según la cual todas las personas, tanto niños como adultos, han } \\
\text { de ser partícipes de sus propios procesos de aprendizaje de manera } \\
\text { activa y propositiva, y especialmente pudiendo disfrutar y divertirse } \\
\text { en este proceso. Se entiende que las relaciones más estrechas y ho- } \\
\text { rizontales facilitan procesos más auténticos y genuinos de comuni- } \\
\text { cación, diálogo y entendimiento. Se oponen a que la programación, } \\
\text { el método de aprendizaje, y los recursos estén reservados solo a los } \\
\text { docentes. }\end{array}$ \\
\hline $\begin{array}{l}\text { Por qué decimos } \\
\text { que dicen lo que } \\
\text { dicen }\end{array}$ & $\begin{array}{l}\text { Se dice que los cursos son entretenidos cuando es posible hacer ami- } \\
\text { gos, cuando en clase se realizan más prácticas, se conversa sobre lo } \\
\text { que a la infancia le interesa, y cuando los cursos no son muy teóricos, } \\
\text { porque los niños al poder aportar con sus propias opiniones y pudien- } \\
\text { do poner en práctica sus conocimientos se genera un ambiente de } \\
\text { mayor riqueza educativa y un mayor aprendizaje. Se dice esto porque } \\
\text { los niños al estar más inmersos en los quehaceres educativos logran } \\
\text { involucrarse y hacer propios los espacios educativos, es por ello que } \\
\text { se dice que prefieren hacer cuestiones más prácticas, donde puedan } \\
\text { mostrar o exponer sus intereses, que aprender cuestiones más teóricas } \\
\text { y de memoria. Se dice que cuando la metodología en educación es } \\
\text { alternativa a la que tradicionalmente se imparte en la escuela, la in- } \\
\text { fancia alcanza un mayor protagonismo, se dice esto porque en la me- } \\
\text { dida que los profesores dispongan en el aula una actitud más cercana, } \\
\text { y una proximidad relacional con la infancia se genera un proceso de } \\
\text { formación más genuino, igualitario y colaborativo. }\end{array}$ \\
\hline
\end{tabular}

Tabla 7. Fragmento Matriz Inferencia discursiva. Ejemplo: Subcategoría Metodología/Pedagogía, categoría Percepciones y valoraciones sistema escolar

El estudio, análisis y reflexión de todas las matrices elaboradas concluyó en la configuración de las distintas posiciones discursivas sobre las representaciones sociales que tiene la infancia sobre el Mundo adulto. Se define cada posición discursiva, el tipo de relaciones entre ellas y sus representaciones gráficas.

Siendo ocho las posiciones discursivas que dan cuenta de las representaciones que la infancia tiene del mundo adulto, tal como se puede observar en la siguiente figura, a saber: (A) Adultocéntrica, (B) Contraadultocéntrica, (C) Exoadultocen- 
trica, (D) Crítica Adultez, (E) Normativa/Performativa, (F) Materno/Paternal, (G) Mundos Opuestos, y (H) Sexista.

Según la posición (A) Adultocéntrica, que se configura como la posición dominante, las representaciones sociales que la infancia tiene del mundo adulto están relacionadas con una idea de sabiduría cristalizada, exclusiva del mundo adulto. Serían las figuras poseedoras del saber y de la verdad. Saber del cual se considera que la infancia aún carece, por lo que se deposita la sapiencia en la adultez. La experiencia y los años serían garantía de conocimiento y reconocimiento social: "Es que no, es que ese no es el problema, tú decís que piensa en ella [la profesora], pero está pensando en ti también porque... tú después vai a estar mal y vai a decir, pucha por qué no le hice caso (G.1)". "Yo no les contesto porque tienen la razón, cuando nos retan, nos retan con razón..." (G.9).

La niñez sobrevalora el saber de los adultos en desmedro del propio. Las personas adultas son vistas como personas capaces y eficaces, a diferencia de la niñez que tiende a infravalorarse: "pero qué tiene, si yo no soy profesora, no soy nadie, soy una alumna [...] Es que no puedes comparar un alumno con un profesor... el profesor tiene mucho más cargo que un compañero" (G.1).

Al considerar a la adultez como referente, las practicas o actividades de los niños y niñas son evaluadas en comparación a las realizadas por los adultos, por tanto, las valoraciones que la infancia hace de sí misma, son negativas. Además, necesitan de la guía y aprobación adulta: "Pero lo que pasa es que somos medio desordenaos... Este año estamos peores que el año pasado. Este año como nos cambiaron profesores, ya no estamos más tiempo con el profe Marcos... Igual lo echamos de menos. Es más difícil" (G.3).

La Posición (B) Contraadultocéntrica, que se opone a la anterior, la posición (A) Adultocéntrica, cuestiona la idea de que sostiene que las personas adultas son las poseedoras del conocimiento y la verdad. Se dice que las personas adultas se validan recurriendo al simple hecho de ser mayores, de ser adultos respecto de la infancia: "ellos siempre van a querer tener la razón... ellos nos van a ganar siempre... no podemos decir nada, porque como ellos son adultos y entre ellos se entienden... y como son amigos de trabajo se ayudan entre ellos... son colegas ${ }^{8} "($ G.1).

Según esta posición, se cuestiona que la sabiduría venga dada por el simple hecho de tener más o menos años. Se oponen a que los adultos no consideran válidos los saberes de la infancia ni sus opiniones por el solo hecho de ser niños: "pero es que generalmente dicen, es la edad, es muy cargante, es muy cargante [...] estamos respondiendo de buena forma no lo toman en consideración porque somos niños [hablando con vos infantilizada]... y a eso es lo que yo voy... uno debería de dar la idea que tenga... se supone que si ellos piden respeto, deberían respetar nuestras opiniones también, y no lo hacen, todo porque creen que somos chicos, o somos inmaduros y no tenemos una opinión suficientemente buena para ellos...” (G.1).

\footnotetext{
${ }^{7}$ Pucha es una locución verbal de lamento.

${ }^{8}$ Colega es una locución para referirse a compañero de trabajo o profesión.
} 
Se dice que los adultos creen que los niños carecen de capacidad para emitir opiniones con fundamento: "iAh no! me carga, que nos dicen, ah, es que los adolescentes nos bipolares, somos adolescentes, no somos estúpidos, y nos tratan como ah ya, es adolescente, es adolescente, es cargante eso, bueno, a mí me carga [...] A mí me da la impresión a veces que se creen que saben todo, y no..." (G.1). Se afirma que los adultos intentan imponer cómo se ha de comportar la infancia, sin ponerse en su lugar ni considerar cómo esta aprende y se relaciona: "nos gritan y uno se pone peor, entonces en esos casos los profesores no se ponen a pensar en los alumnos. Es que tienen que ser empáticos” (G.1).

La posición (C) Crítica adultez, que es afín a la (B) Contraadultocéntrica, habla de lo contradictorios e inconsistentes que son las personas adultas. Se dice que constantemente cambian de parecer dependiendo del contexto y de su conveniencia y acomodo: "son terrible de bipolares algunos, porque dicen, ya escuchen música, y luego, ya, que pásame el celular y te lo doy al final. Sí, así son muy bipolares" (G.3).

Se sostiene que los profesores exigen el cumplimiento de normas que ellos no respetan, lo que dificulta un respeto mutuo: "Mal poh, si ellos quieren respecto que nos respeten también a nosotros [...] llega gritando a la sala por cualquier cosa, y nosotros le decimos, tía baje la voz y dice no me griten si no estoy gritando y grita más fuerte... Pero si ustedes estaban gritando, y no poh, si estábamos callados" (G.8)

Se dice que los adultos son inconstantes, que cambian constantemente sus criterios y exigencias: "era como que ya, hagan esta actividad, o hagan un mapa conceptual... y al día siguiente, borren la actividad y háganlas de nuevo..." (G.7). Se dice que entre ellos no llegan a acuerdos: "Así como que mi papá me dice, ya oh, anda y mi mamá dice, pero no, que le puede pasar algo..." (G.3).

Se sostiene que los adultos en ocasiones entregan dobles mensajes, y en ocasiones acomodan sus discursos según las circunstancias, lo que genera confusión en la infancia: "le digo mamá si es que a todo el curso le fue mal, y dicen no, a mí me importa tú nota... y sí poh, dice no me importan los demás, y después ah, y ¿por qué a tus compañeros les fue bien? iSí! (G.9).

Según esta posición (D) Exoadultocentrica, que tiene afinidad con la (B) Contraadultocéntrica y se diferencia de la posición (A) Adultocéntrica, se considera que cada etapa del ciclo vital es ardua y complicada, que todo momento tiene sus bondades y complejidades: "es que obviamente tratamos de ponernos en el lugar de otros, porque tampoco ser adulto no es fácil, niño tampoco es fácil" (G.1).

Se sostiene que la madurez y la sabiduría vienen dadas por los itinerarios vitales más que por los años que se tenga, se dice que hay niños que pueden ser mucho más maduros que muchos adultos: "es que la edad no importa como puede ser la vida, porque puede que una niña de doce años puede que haya pasado por mucho, más que una persona de cincuenta y siete, me da igual... porque a una niña de doce años la pudieron haber violado, o la pueden haber abusado,

\footnotetext{
${ }^{9}$ Tía y tío es una forma para referirse en algunos colegios a las y los profesores.
} 
algunos inconvenientes que una persona de cincuenta y ocho nunca ha pasado por eso poh, entonces me carga cuando dicen, ah es la edad... la edad es como un número más de vida, porque uno puede tener trece años y puede ser mucho más madura o mucho menos inmadura de otra persona de no sé, de más edad" (G.1).

Se dice que a los adultos se les respeta, pero que no por el hecho de ser adultos se les ha de permitir que puedan faltar el respeto a la infancia: " $O$ sea, yo, $a$ mi papi y a mi mami, a todos los que son adultos, yo los respeto, y pero aunque no sean de la familia y me dicen algo malo, yo le respondo..." (G.10).

(E) Normativa performativa. Esta posición, al igual que la (F) Materno/paternal, es afín a la posición (A) Adultocéntrica. Según esta posición, los adultos son percibidos como personas estrictas y rígidas que imponen normas siguiendo estrategias de control y dominio, basadas principalmente en generar temor a los niños y niñas: "se enoja cuando uno le pregunta... dice pregunten y alguien le pregunta, y dice, ¿pero cómo que no entendió?... es que, aprendemos con ella porque le tenemos miedo... es que la profesora dijo es que ustedes no tienen que tener miedo conmigo, y cuando yo tengo una duda con algo, la miro y como que... da miedo" (G.6).

Según se dice, los adultos utilizarían represivos mecanismos de control, impidiendo u obstaculizando que los niños puedan expresarse y exponer sus dudas o sus ideas. La infancia teme equivocarse, ve a los adultos como figuras a las que tiene que obedecer, aunque no se esté de acuerdo, lo hace solo para evitar sanciones: "Es que a la tía le tenemos miedo ... porque si hacíamos alguna cosa... nos cae mal y nos va a dejar repitiendo ${ }^{10}$ la vieja esa, esa señora. $Y$ ha dejado repitiendo ya [...] poh si no hay que decirle nada... sino al tiro ${ }^{11}$ se enoja, además pa que no me agarre mala, sino después me deja repitiendo... Es que me da miedo hablar (G.8).

La posición (F) Materno/Paternal es afín a la posición (A) Adultocéntrica. Según esta posición, loas personas adultas son vistos por los niños y niñas como personas frágiles y débiles, como personas vulnerables a quienes se les ha de proteger. Se dice que la niñez, en su afán de cuidar a la población adulta, no expresa lo que realmente piensa. No formulan críticas para no generales daño o herir sensibilidades: "Es que a mí me da pena, no me gusta decirle a los profesores que son fomes ${ }^{12}$, que no son buenos enseñando... porque me da pena, porque sacó su doctorado y va pa'llá con sus chalitas ${ }^{13}$ feas, lleva sus libros, prepara el terreno, y decirle, oiga profe es fome... ¿te cahai ${ }^{14}$ ? No, qué desgraciá..." (G.5). Se justifica la actitudes y comportamiento de las personas adultas, pues se considera que atraviesan por un momento complejo de la vida: "porque tampoco ser adulto no es fácil" (G.2).

10 Repetir es el verbo usado para suspender un curso.

11 Al tiro es una típica locución adverbial chilena para decir inmediatamente.

12 Fome es un adjetivo para referirse a algo sin gracia, aburrido, molesto.

13 Chalas y chalitas son los nombres sustantivos para referirse a sandalias.

14 Cachai, deriva del verbo cachar que es el que se usa para referirse a entender o comprender. 
La infancia justifica las actitudes hostiles que pueden tener los adultos, minimizándole su importancia, en cuestiones externas a las relaciones que mantienen con la infancia "a lo mejor tienen problemas en la casa y se vienen a desquitar aquî" (G.8).

A los adultos de mayor edad se los consideran aún más frágiles, generándose una suerte de cuidado compasivo hacia la adultez: "Es que él no sabe, aonde es muy viejito. Es que es mayor. Es que como que no tiene educación... en... en nada" (G.10).

Según la posición (G) Mundos opuestos, que es afín a la (C) Crítica Adultez y difiere de la (A) Adultocéntrica. La infancia considera que los adultos y los niños son personas incompatibles, como si entre ambos grupos no existiesen puntos de encuentro. Niños y niñas visualizan a las personas adultas como figuras lejanas y ajenas a las realidades de la infancia: "Porque hay profesores que como que no les interesa, porque lo único que les interesa es la plata ${ }^{15}$ " (G.10). "pero no que me diga ven a sentarte conmigo, hablemos algo, es como extraño, o que me pregunten qué te paso hoy día [...] igual es extraño, es que ya no soy una niñita, ya no me gusta conversar de eso con mis padres, es como raro ..." (G.4). Se dice que los profesores se irritan al trabajar con los niños y niñas y que son crueles, ya que intentan mostrar a los niños el disgusto que les generar el trabajar con ellos: "Entra así enojao, así cansado. Además que es que viene así muy grave ${ }^{16}$. Como que sale de la sala y sonríe y se va contento, como que nos odia. Como que sale de la sala de nosotros y se pone contento" (G.3). "Mientras más jóvenes más simpáticos, cuando son más mayores como que ya están chatos $^{17}$, están chatos de nosotros" (G.6).

Se sostiene que los adultos solo están centrados en sí mismos, sin considerar lo que le ocurra y sientan niños y niñas: "y mi papá cree que con eso queda genial, y me está haciendo quedar mal" (G.5). "Pero es que si nos conocieran en verdad no dirían lo mismo" (G.5).

Dicen que es paradójico, ya que ellos alguna vez fueron niños y se sintieron así. Se dice que son arrogantes porque pareciera que hubiesen perdido la memoria: "Es que no nos entienden, porque ellos igual fueron como nosotros, tuvieron que haber sido como nosotros... No los crearon siendo como son ahora" (G.5) "es como si ellos en el colegio hubieran sido perfectos, es que esa es la cuestión, como si ellos fueron perfectos, eso es lo que ellos pretenden demostrar que fueron perfectos" (G.3).

Según la posición (H) Sexista, que es afín a la posición (A) Adultocéntrica, la infancia considera que existen dos tipos de personas adultas, dependiendo del sexo-género al que pertenezcan. Construyen distintas imágenes para hombres y mujeres. Se dice que las mujeres tienden a ser más inseguras con los niños, y a ejercer una sobreprotección. Los padres son percibidos menos protectores pero

\footnotetext{
15 Plata es el dinero.

16 Ser grave, locución verbal para referirse a alguien serio y de mal humor, siendo exagerado.

17 Se usa en la locución verbal estar chato cuando se tiene la sensación de estar muy cansado y con poca paciencia.
} 
más autoritarios: "Como que las mamás no quiere que crezcan [...] como que la mamá es eso, y el papá no tanto. La mamá no quiere que crezca uno, que se quede así siempre (G.3). "a mí todavía me ve como guagua ${ }^{18}$ de pecho. A mí todavía me dice mi bebé. A mí también me dice lo mismo. Es que es normal poh, es el amor de mamá... (G.4). "pero mi mamá es como muy sobreprotectora conmigo, como que yo soy su bebe y todo. Sí, son muy sobreprotectores" (G.3). "mi papá a las nueve ya le gusta que esté durmiendo y llama todos los días pa saber si estoy durmiendo...” (G.4).

Enunciadas y definidas las características de cada una de las posiciones y señalada la tipología de relaciones que mantienen entre sí, al objeto de facilitar la percepción de la estructura relacional de las posiciones discursivas se procedió a exponer la representación gráfica de la misma, tal como se puede apreciar en la figura 1.

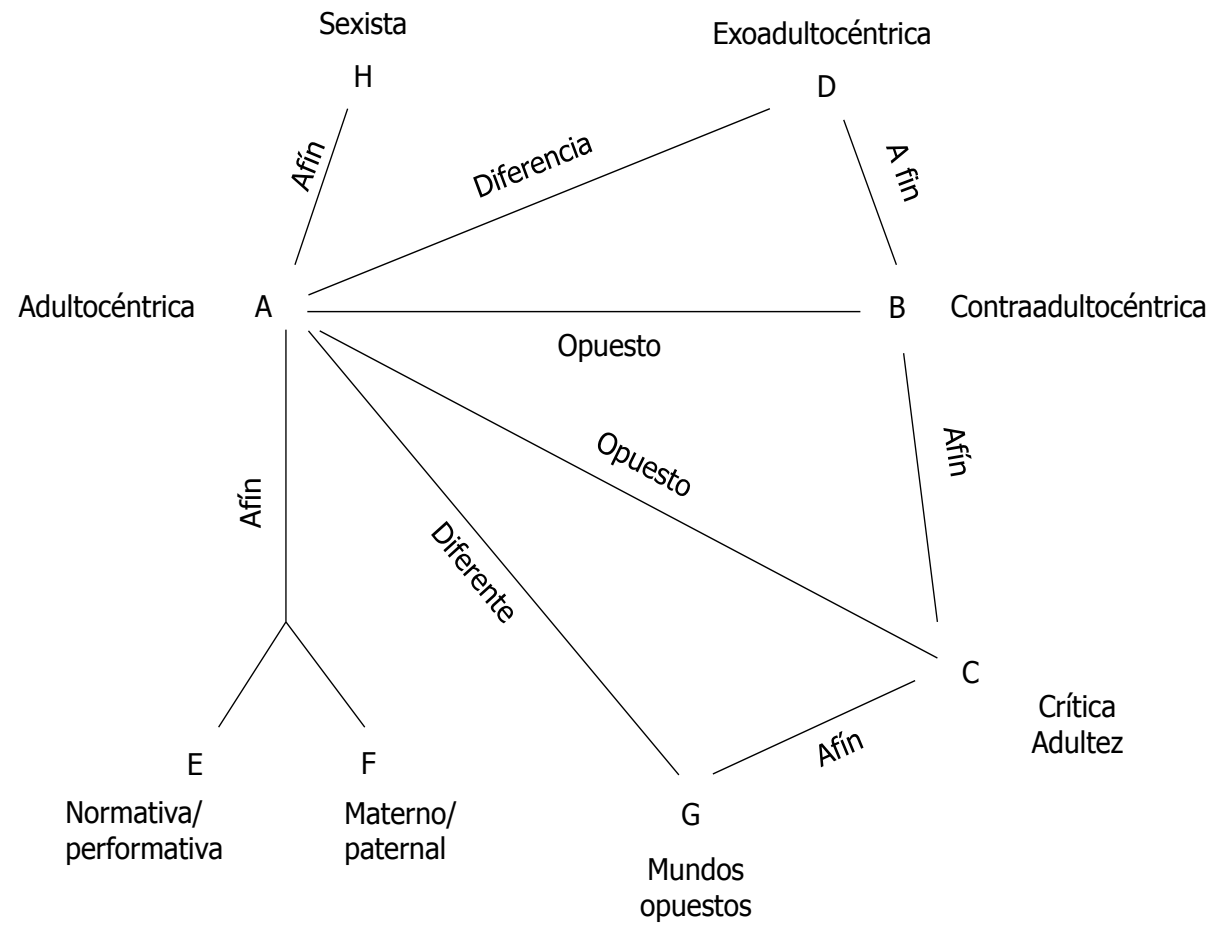

Figura 1. Posiciones discursivas sobre el mundo adulto

${ }^{18}$ Guagua es la expresión para referirse a un bebe, una niña o niño pequeño 


\section{CONCLUSIONES}

La posición discursiva dominante sobre las representaciones sociales que la infancia tiene del mundo adulto es adultocéntrica. Los adultos constituyen el modelo a seguir. La infancia toma la figura de la persona adulta como referencia, la cual orienta su afán, aspiraciones y en la que ha de convertirse. Esta imagen del mundo adulto propicia que las relaciones que con él se establecen sean asimétricas, pues la infancia considera que son las personas adultas quienes han de establecer las normas, las reglas y las diversas expresiones de su relación, así como las negociaciones que esta relación suponga. Frente a la dominante posición Adultocéntrica, la investigación constata la existencia de otras posiciones que, aunque con menos presencia, son disientes de ésta. Las posiciones "disidentes a las adultocentradas" tienen una imagen del mundo adulto menos idealizada y enaltecida, ven a las y los adultos tanto como sujetos sabedores como ingenuos. Desmitifican la clásica figura adulta, valoran sus saberes y sus capacidades, pero no más que los propios. Consideran que las personas adultas, al igual que niños y niñas, son sujetos en proceso, en aprendizaje, que comenten fallos, y que sus lecturas e interpretaciones pueden no ser las más adecuadas. De acuerdo con estas imágenes se aboga por establecer relaciones más simétricas con el mundo adulto. Niños y niñas saben que ambos, tanto la adultez como la niñez, pueden aprender del otro, que son complementarios, se retroalimentan y ambos pueden contribuir con saberes y capacidades diferentes, lo que sugiere un compromiso relacional. Este compromiso defiende que los intercambios con la adultez se basen en la confianza mutua, asimismo, que las y los adultos establezcan relaciones más flexibles con la infancia en espacios de diálogo y entendimiento. Cuando esto acontece, la infancia construye una imagen de los adultos más plástica, al tiempo que se empodera y su autoimagen se fortalece, viéndose más autónoma y segura.

Las conclusiones de la investigación ilustran de manera eficiente y efectiva la propuesta metodológica formulada en este artículo. Las reuniones realizadas siguiendo el diseño de una muestra estructural según los ejes estructurales definidos de acuerdo con la problemática objeto de estudio -definido/delimitado por una temática, una población y un ámbito espaciotemporal y socioeconómico cultural- generan la pertinente materia discursiva, cuyo análisis proporciona la formulación de una estructura discursiva constituida por posiciones discursivas relacionadas entre sí, las cuales pueden ser condensadas en dos grandes posiciones. En cada una de ellas quedan englobadas otras que respectivamente se muestran más o menos afines, diferentes o complementarias.

Esta propuesta propicia conocer tanto el contenido y las relaciones globales como el contenido de cada una de las posiciones articuladas entre sí. Información de gran utilidad en el diseño de programa, acciones, intervenciones sociales, planes de comunicación, campañas de publicidad o de relaciones públicas etc., ya que, siguiendo la máxima freireana, una exitosa estrategia social requiere aunar afinidades, diferencias e incluso ajenidades con la que contrarrestar las posiciones discursivas antagónicas. 


\section{BIBLIOGRAFÍA}

ALONSO, L. E. (1998): La mirada cualitativa en Sociología, Madrid, Fundamentos BENVENITE, E. (1971): Problemas de lingüística general, México, Siglo XXI

CALLEJO, J. (2001): El Grupo de discusión: introducción a una práctica de investigación, Barcelona, Ariel

CANALES, M. (2006): Metodologías de investigación social. Introducción a los oficios, Santiago de Chile, LOM Ediciones

CANALES, M., OPAZO, A. y COTTET, P. (2016): Ciencias Sociales: singularidad histórica y reflexividad, en Aportes teóricos y metodológicos para una investigación social situada, Antofagasta, Editorial Universidad Católica del Norte

CONDE, F. (2010): Análisis sociológico del sistema de discursos, Cuadernos Metodológicos, 43. Madrid, España. Centro de Investigaciones Sociológicas (CIS)

GEE, P. (2005): La ideología en los discursos, Madrid, España, Ediciones Morata

GUTIÉRREZ, J. (2008). Dinámica del grupo de discusión, Cuadernos Metodológicos, 41, Madrid, España, Centro de Investigaciones Sociológicas (CIS)

IBÁÑEZ, J. (2003): Más allá de la sociología. El grupo de discusión. Teoría y Práctica, Madrid, Siglo XXI

IBÁÑEZ, J. (1985): Del algoritmo al sujeto. Perspectivas de la investigación social, Madrid, España, Siglo XXI

IBÁÑEZ, J. (1986). "Perspectivas de investigación social: El diseño en las tres perspectivas, en Manuel García Ferrando, Jesús Ibáñez y Francisco Alvira (Ed.), El análisis de la realidad Social. Métodos y técnicas de investigación, Madrid, España, Alianza Editorial, pp. 57-98

IOÉ, Colectivo (2010): “¿Para qué sirve el grupo de discusión? Una revisión crítica del uso de técnicas grupales en los estudios sobre migraciones", EMPIRIA. Revista de Metodología de Ciencias Sociales, 19, pp. 73-99

LAY, S. y MONTAÑÉS, M. (2013): "Las Representaciones Sociales del mundo adulto sobre la infancia y la participación infantil", Revista Salud y Sociedad, 4(3), pp. 304-316

LAY-LISBOA, S. y Montañés, M. (2018): "De La Participación Adultocéntrica a La Disidente: La Otra Participación Infantil.” Psicoperspectivas. Individuo y Sociedad, 17 (2), pp. 1-12

MARTÍNEZ, M. (2006): “La investigación cualitativa (Síntesis conceptual)”, Revista de Investigación en Psicología, 9(1), pp.123-146

MEJÍA, J. (2000): El muestreo en la investigación cualitativa, Revista Investigaciones Sociales, 5, pp. 165-80

MERTON, R. K., FISKE, M. y KENDALL, P.L. (1956): "The Focussed interview", American Journal of Sociology, 6, pp. 541-557

MONTAÑÉS, M. (2013): Diseño científico de muestras estructurales (II), en Espacios de comunicación: IV Congreso Internacional de la Asociación Española de Investigación en Comunicación, pág. 1835 y ss.

MONTAÑÉS, M. (2013): Diseño científico de muestras estructurales, en Investigar la Comunicación hoy. Revisión de políticas científicas y aportaciones metodológicas: Simposio Internacional sobre Política Científica en Comunicación / coord. por Vicente, M, et all. Vol. 4,2013 (Comunicaciones 4), págs. 841-856

MONTAÑ́́S, M. (2012): "Verdad e incertidumbre. Una mirada desde la perspectiva sociopráxica", Prisma. Revista de ciencias sociales. Investigación social, 8, pp. 440469. 
MONTAÑÉS, M. (2010): El grupo de discusión. Cuadernos CIMAS, disponible en http://www.redcimas.org/biblioteca/metodologia/ [consulta: 10-8-2018]

MONTAÑÉS, M. (2009): Metodología y técnica participativa, teoría y práctica de una estrategia de investigación participativa, Barcelona, España, Editorial UOC.

MONTANÉS, M. (2002): "Interpretación de textos y discursos al servicio del desarrollo local”, en Metodologías y presupuestos participativos, Madrid, IEPALA editorial, pp. 77-122)

MONTAÑÉS, M., y LAY, S. (2017): La muestra estructural: fundamentos y procedimiento, en Actas XXXI Congreso Latinoamericano de Sociología, Montevideo, Uruguay

MONTAÑÉS, M., y LAY, S. (2016): Contribución al corpus teórico de la muestra estructural, en Actas XII Congreso Español de Sociología, Gijón, España

MOTA de CABRERA, C. y VILLALOBOS, J. (2007). "El aspecto socio-cultural del pensamiento y del lenguaje: visión Vygotskyana", Educere Revista Venezolana de Educación, 11(38), pp. 411-418

RUÍZ, J. (2009): “Análisis sociológico del discurso: métodos y lógicas”, Revista Forum: Qualitative social research, 10(2), pp. 26

WERTSCH, J. V. (1991): “A sociocultural approach to socially shared cognition”, en L. B. Resnick, J. M. Levine, y S. D. Teasley (Comps.), Perspectives on socially shared cognition, Washington, DC, American Psychological Association, pp. 85-100

WETHERELL, M. y POTTER, J. (1996): "El análisis del discurso y la identificación de repertorios interpretativos", en Gordo A.J y Linaza, J.L., Psicologías, Discurso y Poder (PDP), España, Visor, cap. 2

VILLASANTE, T. (2006): Desbordes creativos. Estilos y estrategias para la transformación social, Madrid, La Catarata 
